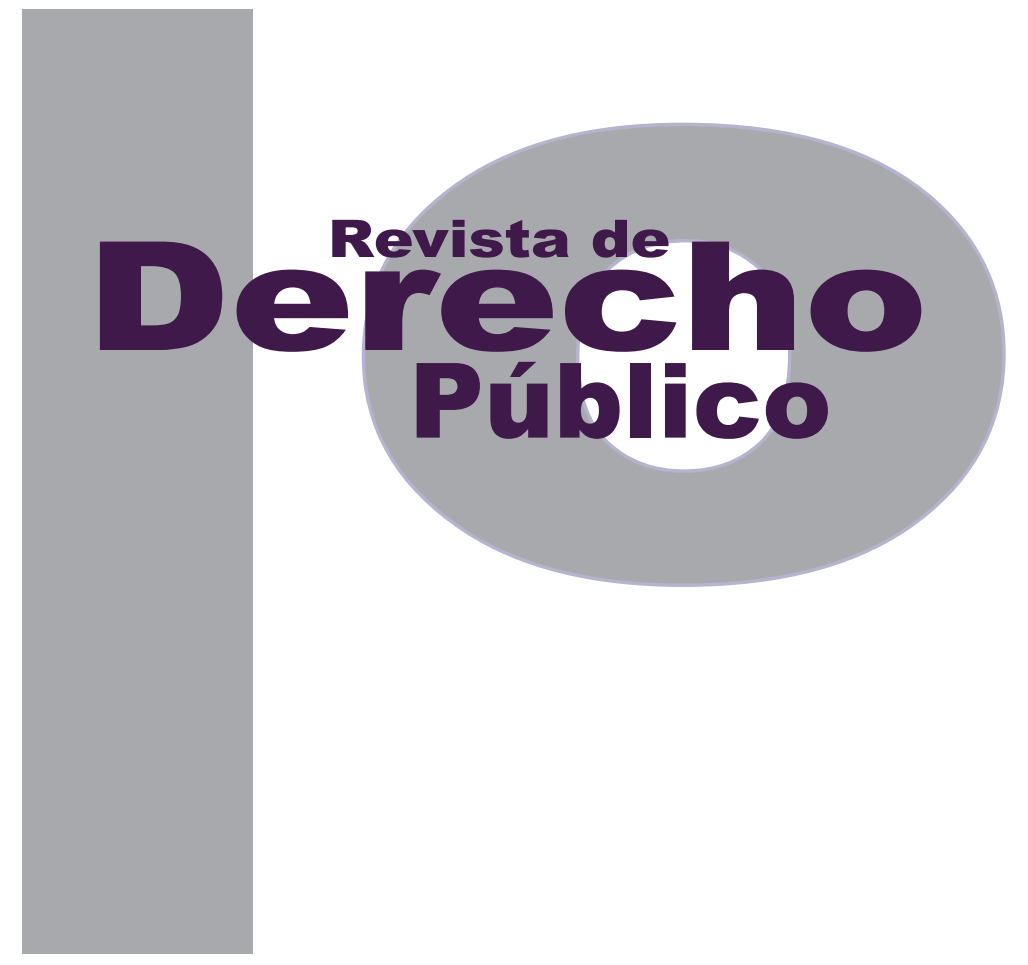

\title{
LIBERALISMO MODERNO: UNA FORMA REFINADA DE COLONIZACIÓN. \\ UN ACERCAMIENTO AL LIBERALISMO DEL SIGLO XIX A TRAVÉS DE LAS IDEAS DE FLORENTINO GONZÁLEZ
}

\author{
AdELAIDA MARÍA IBARRA PADILLA
}

Revisión de tema

DOI: http://dx.doi.org/10.15425/redepub.34.2015.23

Universidad de los Andes

Facultad de Derecho

Revista de Derecho Público N. ${ }^{\circ} 34$

Enero - Junio de 2015. ISSN 1909-7778 


\title{
Liberalismo moderno: una forma refinada de colonización. Un acercamiento al liberalismo del siglo XIX a través de las ideas de Florentino González
}

\section{Resumen}

El presente trabajo tiene por objeto hacer un análisis crítico de los principios liberales imperantes en la Colombia postcolonial del siglo XIX, principalmente a través de la obra de Florentino González. En cuanto a su alcance, el artículo aborda diferentes facetas del liberalismo de la época, tales como la relación entre costumbre y ley, la separación IglesiaEstado, la tensión federalismo-centralismo, el sufragio universal y la democracia ilustrada, a la luz de lo que actualmente entendemos por principios liberales. Como resultado se encuentra que el liberalismo del siglo XIX se caracterizó por servirse de un argumento civilizador para segregar y discriminar a la mayor parte de la población.

Palabras clave: liberalismo, soberanía individual, civilización, democracia ilustrada, separación Iglesia-Estado, relación costumbre-ley.

\section{Modern Liberalism: a refined form of colonization. An approach to the liberalism of the nineteenth century through the ideas of Florentino González}

\begin{abstract}
This paper aims to make a critical analysis of the prevailing liberal principles in the postcolonial Colombia, mainly through the work of Florentino González. As regards the scope, the paper deals with different aspects of liberalism of the nineteenth century such as the relationship between custom and law, the separation of church and state, the strain between federalism and centralism, universal suffrage and enlightened democracy of what is currently mean by liberal principles. The result is that the liberalism of the nineteenth century was marked by the use of a civilizing argument to segregate and discriminate most of the population.

Keywords: liberalism, individual sovereignty, civilization, enlightened democracy, church-state separation, custom-law relationship.

\section{Liberalismo moderno: uma forma refinada de colonização. Uma aproximação ao liberalismo do século XIX através das ideias de Florentino González}

\section{Resumo}

O presente trabalho tem como objetivo fazer uma análise crítica dos princípios liberais imperantes na Colômbia póscolonial do século XIX, principalmente através da obra de Florentino González. Sobre seu alcance, o artigo aborda diferentes facetas do liberalismo da época, tais como a relação entre costume e lei, a separação Igreja-Estado, a tensão federalismo-centralismo, o sufrágio universal e a democracia ilustrada, à luz do que atualmente entendemos por princípios liberais. Como resultado se encontra que o liberalismo do século XIX se caracterizou por servir-se de um argumento civilizador para segregar e discriminar à maior parte da população.
\end{abstract}

Palavras-chave: liberalismo, soberania individual, civilização, democracia ilustrada, separação Igreja-Estado, relação costume e lei. 


\title{
Liberalismo moderno: una forma refinada de colonización. Un acercamiento al liberalismo del siglo XIX a través de las ideas de Florentino González*
}

\author{
Adelaida María Ibarra Padilla*
}

\section{SUMARIO}

Introducción - I. ACERCA DE LA LEY Y SU RELACIÓN CON LA COSTUMBRE - II. LA EMANCIPACIÓN DEL ESTADO FRENTE A LA IGLESIA EN COLOMBIA - III. UNIVERSALIDAD Y ATEMPORALIDAD DE LA LEY - IV. EL LEGISLADOR REFORMISTA - V. CONCLUSIONES - Referencias.

\footnotetext{
* Cómo citar este artículo: Ibarra Padilla, A. M. (Junio, 2015). Liberalismo moderno: una forma refinada de colonización. Un acercamiento al liberalismo del siglo XIX a través de las ideas de Florentino González. Revista de Derecho Público, 34. Universidad de los Andes (Colombia).

Corresponde a los resultados del trabajo de reflexión desarrollado por la autora en el marco de la asignatura Teoría del Derecho I, del Doctorado en Derecho que adelanta en la Universidad de los Andes.
}

** Abogada, Universidad del Atlántico (Colombia), Magíster en Derecho, Universidad del Norte (Colombia). Magíster en Administración, Universität Leuphana Lüneburg (Alemania). Estudiante de Doctorado en Derecho, Universidad de los Andes. Correo: am.ibarra10@uniandes.edu.co 


\section{Introducción}

Uno de los principales exponentes del liberalismo colombiano a mediados del siglo XIX fue Florentino González. ${ }^{1}$ Su tesis central sostenía que no son las leyes las que deben adecuarse a las costumbres de los pueblos, sino las costumbres de los pueblos las que son forjadas por medio de las leyes. En este sentido, el camino a la civilización de los pueblos se hallaría en la adopción de buenas leyes que crearan, a través de su continua aplicación, buenas costumbres.

Esta tesis, desde mi punto de vista, oculta un discurso fuertemente colonialista, en el que las leyes son utilizadas como un instrumento de dominación. Un discurso que supone, de un lado, la existencia previa de un legislador civilizado y sabio, y de otro, un pueblo con unas costumbres bárbaras que corregir. Las leyes no serían más que meras imposiciones de un legislador opresor, que define lo que es bueno para el pueblo. Por tanto, se trata de un legislador que busca

1 José Nazario Florentino González Vargas, (Cincelada, Santander, 1805 - Buenos Aires, 1874), fue un liberal radical, periodista, jurista, economista, político y profesor de Derecho Constitucional. En 1831 fue secretario de la Convención Constituyente de los departamentos de Nueva Granada. En 1833 fue elegido representante al Congreso por El Socorro, y lo mismo sucedió en 1839. Entre 1834 y 1836 ejerció interinamente los cargos de secretario de Hacienda, de lo Interior y de Relaciones Exteriores, y luego, la gobernación de la provincia de Bogotá. En 1846, Tomás Cipriano de Mosquera lo designó secretario de Hacienda. En 1848 fue candidato a la Presidencia de la República. En el mismo año, viajó como encargado de negocios a Francia y Gran Bretaña. Del 6 de febrero de 1854 a 1858, fue procurador de la Nación. En la generación del radicalismo, Florentino González tuvo una eminente posición, promovió la libertad de comercio, la liberación del poder clerical, las relaciones exteriores, el fortalecimiento de las provincias, la organización del régimen progresivo de los impuestos, la eliminación de la usura y la rebaja de intereses para el incremento de la producción. El radicalismo liberal es vencido por la fuerza de la Regeneración conservadora de Rafael Núñez y Miguel Antonio Caro que culminó con la Constitución de 1863 (Círculo de Lectores. Gran Enciclopedia de Colombia, tomo 5, págs. 22-23). acabar con las tradiciones y costumbres que van en contravención de la idea que este tiene de civilización.

La tesis de Florentino González nos lleva entonces a plantearnos varias preguntas: ¿Qué relación existe entre las costumbres y las leyes? ¿Cómo debe ser la relación entre las leyes de la Iglesia y las leyes del Estado? ¿Pueden las buenas leyes ser aplicadas a cualquier pueblo, en cualquier tiempo? ¿Quién debe legislar? El presente trabajo analiza el planteamiento de Florentino González a partir de los cuestionamientos antes señalados.

\section{ACERCA DE LA LEY Y SU RELACIÓN CON LA COSTUMBRE}

Partiendo de la tesis arriba planteada, González consideraba que las buenas leyes son aquellas capaces de crear las instituciones que el país requiere. Sin embargo, para el surgimiento de estas nuevas instituciones era necesario un cambio en las costumbres. "Siempre que la condición de un pueblo se ha mejorado, es porque sus legisladores destruyeron las costumbres que lo mantenían estacionario, y establecieron otras en su lugar" (González, 1981, pág. 247). Las viejas costumbres eran vistas por González, entonces, como un obstáculo para el progreso, ${ }^{2}$ como un elemento maligno que había que destruir para poder mejorar. En esta tesis de Gonzá-

2 Esta idea del progreso se encuentra estrechamente ligada con lo que Peter Fitzpatrick Ilamaría "el mito del Derecho moderno", que consiste en considerar el Derecho como una historia lineal y constante de progreso, que "se desarrolla en la negación de sus orígenes y manifestaciones anteriores, avanzando siempre hacia una diferenciación y autonomía mayores" (1998, pág. 153). 
lez se encuentran muy presentes los postulados de la llustración. ${ }^{3}$

Como señala De Trazegnies en el ideario de la Ilustración, toda tradición debía ser replanteada a la luz de los fines del individuo y de la razón instrumental. Ello significa que las tradiciones no tienen derecho alguno por sí mismas y deben ser más bien objeto de desconfianza y de inspección (1993, pág. 80).

Las costumbres de acuerdo con González, mantienen al pueblo estacionado y, por consiguiente, considerarlas al momento de hacer las reformas constituiría un contrasentido. "Las particularidades culturales son consideradas como elementos retrógrados que dificultan la modernización" (De Trazegnies, 1993, pág. 82).

González afirma también que las costumbres no son innatas a un pueblo sino el resultado de la práctica de los preceptos legales: “Ningún pueblo aprende la costumbre de la libertad en donde la libertad no está establecida (...) Todo lo que el pueblo aprende, lo aprende practicándolo" (1981, pág. 253). Todo cambio de ley conlleva entonces una reforma, es decir, un nuevo modo de ser, unas nuevas costumbres. En otras palabras, las costumbres son impuestas a través de las leyes. ${ }^{4}$

3 Burke, refiriéndose a los ilustrados señala que: "No tienen respeto por la sabiduría de los demás; pero la compensan con una gran confianza en sí mismos. Para ellos el hecho de que un sistema sea viejo es motivo suficiente para destruirlo" (1942, pág. 117).

4 Esta postura no es muy diferente a la sostenida por Hobbes, para quien lo primero es el poder coercitivo: "Antes de que puedan tener un adecuado lugar las denominaciones de justo e injusto, debe existir un poder coercitivo que compela a los hombres al cumplimiento de sus pactos por el temor de algún castigo más grande que el beneficio que
Dentro de los detractores del liberalismo se encuentra Burke, para quien los prejuicios (o costumbre en González) son más importantes que la razón individual. Para este pensador político irlandés los prejuicios tienen una razón detrás: la de los ancestros, de la tradición y del pasado. Refiriéndose a la postura inglesa frente al liberalismo pregonado por la Revolución francesa sostiene:

Tenemos miedo a hacer que los hombres vivan y se relacionen basándose en su depósito personal de razón; porque sospechamos que el depósito de cada hombre es pequeño y que harían mejor los individuos aprovechando el banco general y el capital común de los tiempos (Burke, 1942, pág. 116).

González sostiene que quienes se oponen a las reformas no son las costumbres del pueblo, sino las costumbres de las clases privilegiadas que ven en las nuevas instituciones una amenaza. "Las costumbres de las clases privilegiadas, que se han enseñoreado de los diferentes pueblos, y que quieren continuar explotándolos a su agrado. Estas son las costumbres que se oponen a las reformas", mientras que, por lo contrario, “El pueblo está siempre preparado a recibir la obra de los grandes legisladores" (González, 1981, pág. 249). ${ }^{5}$

esperaban del quebrantamiento de su compromiso" (1979, pág. 118). En este sentido, la ley sería lo primero y la costumbre se desprendería de ella.

5 Sin embargo, llama la atención cómo González incurría en aquello que él mismo criticaba. Este pensador de la época, como la mayor parte de los pertenecientes a las clases privilegiadas de entonces, se oponía al sufragio universal. En efecto, se trataba de una reforma que, al empoderar a los pobres, amenazaba la continuidad de la explotación de las clases populares por parte de las dominantes. 
Acerca de la necesidad de observar las costumbres de un país para la elaboración de sus leyes fundamentales, Rousseau sostiene que las leyes sólo son útiles en sociedades donde las costumbres no están bien arraigadas:

El sabio legislador no comienza por redactar buenas leyes en sí mismas, sino que antes examina si el pueblo al cual las destina es adecuado para recibirlas. (...) La mayor parte de los pueblos, como de los hombres, no son dóciles más que en su juventud: se hacen incorregibles al envejecer. Una vez las costumbres están establecidas y los prejuicios arraigados, es una empresa peligrosa y vana querer reformarlos (1975, pág. 70).

A diferencia de lo que considera Rousseau, para González las leyes no son las que deben adecuarse a los pueblos sino las que deben forjar a los pueblos:

Ningún pueblo aprende la costumbre de la libertad en donde la libertad no está establecida (...) Todo lo que el pueblo aprende, lo aprende practicándolo. (...) El pueblo está siempre preparado a recibir la obra de los grandes legisladores, porque no se llaman grandes legisladores los que hacen grandes códigos de largas leyes, sino los que hacen buenas leyes: es decir, leyes que hagan bien al pueblo (1981, pág. 253).

González sostiene que las leyes fundamentales de un país no deben conformarse a las costumbres y preocupaciones de este, sino plantear las nuevas instituciones que dicho país requiere. Todo cambio de ley conlleva una reforma, un nuevo modo de ser, nuevas costumbres. Por lo tanto, es un contrasentido hablar de reforma si se van a seguir considerando las viejas costumbres.

Siempre que la condición de un pueblo se ha mejorado, es porque sus legisladores destruyeron las costumbres que lo mantenían estacionario, y establecieron otras en su lugar, con la práctica de sus preceptos, que es lo que forma las costumbres; porque las costumbres no son innatas en ningún aspecto (González, 1981, pág. 247).

El autor en comento plantea que la oposición a las reformas no se halla en las costumbres del pueblo, sino en el temor de las clases poderosas de perder sus privilegios en las nuevas instituciones. Pese a sus postulados, en su intervención en el Senado de 1853 sobre el sufragio universal, se opone abiertamente al proyecto de ley que pretendía dar mayor participación política al pueblo. En lugar de salir en defensa de un proyecto que buscaba cambiar arraigadas costumbres excluyentes, y crear unas nuevas donde el pueblo tomaba parte en las decisiones que lo afectan, González saca a relucir un discurso clasista. Este jurista y político liberal señala que no hay utilidad para la nación en la generalización del derecho a elegir y lo restringe a aquellos que según él demuestren tener "algún discernimiento para elegir los mejores" (1981, pág. 271).

Esta idea de leyes que destruyen las costumbres imperantes y son la base del progreso, es el argumento utilizado por González en la lucha por la separación entre la Iglesia y el Estado, lo cual nos conduce al siguiente punto de análisis. 


\section{LA EMANCIPACIÓN DEL ESTADO FRENTE A LA IGLESIA EN COLOMBIA}

Durante la segunda mitad del siglo XIX se observa en los países hispanoamericanos una corriente liberal que propende por la construcción de un orden laico. Una de sus características es la "valoración negativa del poder económico, espiritual y político de la iglesia católica y tentativas de desmantelamiento, en nombre de los principios del liberalismo, de las instituciones que eran las expresiones concretas de dicho poder" (Blancarte, 2008, pág. 88).

\section{En Colombia Florentino González y José María} Samper constituyen un ejemplo de pensadores liberales de la época, defensores de la separación Iglesia-Estado. El primero consideraba que la unión de estas dos instituciones pervertía tanto a la religión como a la política y reclamaba el cese de: "esa unión sacrílega entre los sacerdotes y los gobernantes, que nunca puede servir para buenos fines políticos ni morales, que pervierte la religión y pervierte la política" (González, 1981, pág. 284). En consecuencia, denunciaba que los obispos y sacerdotes eran más funcionarios públicos que pastores de fieles y los acusaba de ser cómplices de la tiranía española. En especial, González criticaba la Inquisición, la cual veía como crimen oficial producto de la liga entre la Iglesia y el Gobierno. ${ }^{6}$

6 "En virtud de esa liga [Iglesia-Estado], y con la fuerza que ella daba a los sacerdotes, fue que se estableció la Inquisición y se cometió por muchos siglos ese crimen oficial con que el fanatismo y los déspotas escandalizaron al mundo. Sin la sanción de los gobiernos la Inquisición no se habría establecido (...). Fueron los gobiernos los que autorizaban el crimen, para valerse de sacerdotes con fines políticos depravados" advertía González (1981, pág. 290).
En este mismo sentido, Montesquieu sostenía que la religión es un instrumento del que se sirven los gobiernos despóticos: "En los Estados despóticos, la religión ejerce más influjo que en todos los demás; es un miedo más añadido a tanto miedo" (1987, pág. 42).

González censuraba, además, la doble moral de las comunidades religiosas, cuyos miembros se presentaban como hombres pobres cuando en realidad gozaban en comunidad de inmensas riquezas (pág. 286) y no dudaba en señalar a la religión y al centralismo andino como medios de opresión:

En la religión, como en la industria, la mentida protección de los gobiernos no es otra cosa que la injerencia indebida en los negocios que son y deben ser de la competencia exclusiva del individuo, injerencia que desnaturaliza esos negocios, y se convierte en medio de opresión y de vejaciones (1981, pág. 276).

Obsérvese cómo en el planteamiento de González, la crítica a la Iglesia no se dirige realmente al aspecto religioso o teológico, sino a lo que Marx denomina la esencia práctica de la religión, que no es otra que intereses económicos:

El dinero envilece a todos los Dioses del hombre y los convierte en una mercancía. El dinero es el valor general de todas las cosas, constituido en sí mismo (...) El dinero es la esencia enajenada del trabajo y de la existencia del hombre, y esta esencia extraña lo domina y es adorada por él (Marx, 2009, pág. 160). ${ }^{7}$

En 1843 Carlos Marx publicó un artículo titulado "Sobre la cuestión judía", en el cual polemizaba con Bruno Bauer acerca de la emancipación política de los judíos en el Estado alemán cristiano. En este, 
Para este último, el cristiano y el burgués encuentran su esencia en la necesidad práctica, en el egoísmo, en un mundo de individuos atomizados que se enfrentan los unos a los otros hostilmente.

José María Samper, por su parte, denunciaba que el poder había caído en manos de minorías del peor carácter porque "las mayorías inteligentes y respetables se han visto ahogadas por una fantasmagoría de votos que en realidad no representan sino las intrigas de los curas y de algunos pelafustanes de parroquia" dando con ello a entender la importante influencia en asuntos políticos que tenían los eclesiásticos desde el púlpito (1969, pág. 234).

Frente a los continuos conflictos que se presentaban por asuntos religiosos, en 1861 señaló como solución la secularización del Estado: "Nada más sencillo que proclamar y hacer efectiva la completa libertad de religiones y cultos, la separación absoluta del Estado y la Iglesia y

\footnotetext{
Marx fue más allá del mero aspecto teológico y la supresión de los privilegios religiosos, al considerar que la emancipación del judío era la emancipación de la sociedad respecto de la esencia empírica del judaísmo, cual es la usura, el egoísmo y el endiosamiento del dinero. En su obra, Marx ofrece una reflexión crítica acerca de los fundamentos de la revolución burguesa y el papel de las instituciones liberales en la emancipación del hombre. Para aquel, la emancipación del hombre no se hallaba en la libertad individual, dado que esta hace que toda persona encuentre en su semejante no la realización sino la limitación de su libertad. Criticaba la propiedad privada por materializarse en el disfrute y disposición arbitrarios del patrimonio sin atender a los demás hombres y a la sociedad. Señaló que la igualdad de libertad individual solo servía para convertir al hombre en ser aislado preocupado de sí mismo. Respecto a la seguridad, sostenía que convertía a la sociedad en un instrumento para el aseguramiento del egoísmo. Marx no encontró en los derechos del hombre y del ciudadano el instrumento de emancipación del individuo sino la legitimación del egoísmo. Tampoco vio la sociedad burguesa como una comunidad política sino como el simple medio para satisfacer la necesidad y el interés privado. Por último, afirmó que la verdadera emancipación no proviene del Estado, sino de la misma sociedad. El Estado no era más que el reflejo de la "esencia práctica" de sus miembros.
}

la independencia del sacerdocio, alejado de las luchas políticas" (Samper, 1969, pág. 228). No obstante lo anterior, en los primeros años de la nación colombiana, la dirigencia criolla orientó sus esfuerzos a la creación de una identidad nacional en torno a la religión católica.

Este mismo papel aglutinador de la religión en una sociedad lo expone Burke (1942, pág. 119) al señalar que "la religión es la base de la sociedad civil y la fuente de todo bien y todo consueIo". A diferencia de González y Samper, el autor presenta la idea de una iglesia protestante independiente que sirve de contrapeso al poder monárquico en Inglaterra y no una iglesia cómplice del gobierno.

En el caso colombiano, la naciente República se caracterizaba por la violencia partidista entre centralistas y federalistas y luego entre conservadores y liberales. Durante el siglo XIX, afirma Múnera (2011), religiosidad y política fueron dos poderosos instrumentos para fomentar en el pueblo sentimientos de pertenencia (pág. 34). Desde una visión geográfica, étnica y económica, dicho autor explica la situación que se vivía de la siguiente manera:

El siglo XIX neogranadino no trajo de herencia simples folclores regionales, sino también un pasado de formación de percepción de las regiones, condicionado por la existencia de geografías físicas distintas y de difícil comunicación, grupos humanos diversos, unas economías que tienden a funcionar con un alto grado de autonomía, e intensos conflictos por el predominio de unas regiones sobre otras (Múnera, 2005, pág. 24). 
Aunque luego de la independencia la Iglesia fue perdiendo ciertos espacios, ${ }^{8}$ siguió jugando un papel central en la vida política y social del país. La fe en la Iglesia Católica y en los partidos Liberal y Conservador fueron los principales elementos identitarios de la población. De esta manera surgió en la segunda mitad del siglo XIX, liderado por Caro y Núñez, el movimiento de la Regeneración:

La regeneración había moldeado la nación colombiana con base en su condición religiosa y en sus raíces hispánicas. La identidad adquiría así un aparente consenso. Según el gramático Caro todos los elementos de la vida material tendían a separar a los seres humanos, y sólo su pertenencia a la religión católica tenía el poder de unirlos (Múnera, 2011, pág. 32).

Múnera (2011), refiriéndose a la construcción de identidades nacionales y regionales, señala cómo estas son inseparables de un propósito político y de unas dinámicas del poder y pone como ejemplo la identidad religiosa. La identidad católica impuesta por Caro como propia y única del país conllevaba, pese a su postura universalista, una segregación consciente de quienes no practicaban este credo.

Como reflejo de aquello se adoptó la Constitución de 1886 "en nombre de Dios, fuente de toda autoridad”. Posteriormente, en el Acto Legislativo 1 de 1947 suscrito por los partidos Li-

8 "En lo relativo a la sustitución de la Iglesia por el Estado en funciones de integración de la vida social cotidiana, se hallan medidas como el control estadístico la búsqueda del control estadístico de los nacimientos, matrimonios y defunciones mediante la creación del registro del estado civil, la secularización de los cementerios, la creación de escuelas laicas, la secularización de las instituciones de salud, entre otros" (Blancarte, 2008, pág. 89). beral y Conservador, se reconoció a la religión católica, apostólica y romana como la oficial de la nación y como una de las bases de la unidad nacional. ${ }^{9}$ En esta Constitución se consagró el gobierno democrático y el derecho al sufragio, la separación de poderes, la protección a la propiedad privada y la libertad. Sin embargo, no reconoció el derecho a la igualdad y se mantuvieron los privilegios provenientes de la época colonial. Respecto al derecho al sufragio, el artículo 173 preveía: “Los ciudadanos que sepan leer y escribir o tengan una renta anual de quinientos pesos, o propiedad inmueble de mil quinientos, votarán para Electores y elegirán directamente Representantes". ${ }^{10}$

Por último, cabe aclarar que la separación de Estado e Iglesia pretendida por Florentino González, en ningún momento contradice la continuidad de la existencia de la religión. ${ }^{11}$ Como señala Marx (2009, pág. 161): “la sociedad burguesa sólo llega a su plenitud en el mundo cristiano". El Estado laico burgués solo crea una democracia formal, que enuncia derechos y libertades que no pueden subsistir realmente en

9 El artículo 40 de la Constitución de 1886, en relación con las religiones diferentes a la católica previó: "Es permitido el ejercicio de todos los cultos que no sean contrarios a la moral cristiana ni a las leyes".

10 Sobre este punto, Múnera (2011, pág. 35) señala: “¿En qué quedaba la unidad de la nación católica y la igualdad de los seres humanos ante Dios si la Constitución de 1886 consagraba la desigualdad ante el Estado al negarle a cuatro quintas partes de la población los derechos básicos de la ciudadanía?".

11 Marx va más allá de la mera crítica a la religión y a la secularización del Estado. Para este, la existencia de la religión es un defecto cuya fuente no se debe buscar en la esencia del Estado mismo, sino en las barreras temporales, es decir, en los elementos materiales. Como explica Calvez (1958, pág. 48) "la religión no puede desaparecer más que cuando haya desaparecido el fundamento profano de la alienación. La religión, efectivamente, no es más que un fenómeno secundario y derivado: la raíz de la alienación está fuera de ella". 
una sociedad civil. El Estado supera aparentemente las diferencias por nacimiento, estamento, cultura, ocupación, cuando las declara como diferencias apolíticas y establece que cada individuo está en igualdad de derechos para participar en la soberanía del pueblo. No obstante, el Estado al proteger la propiedad privada, la cultura, la ocupación, lejos de superar estas diferencias de hecho, son estas las que se constituyen en la condición de su existencia (Lukacs, 1986, págs. 63-64).

\section{UNIVERSALIDAD Y ATEMPORALIDAD DE LA LEY}

González fue un defensor de las ideas liberales y, por tanto, creía en la primacía de la razón, apoyaba el federalismo, rechazaba la unión de Iglesia y Estado, pero sobre todo, veía en la soberanía individual un derecho universal y en la democracia una institución de bondad absoluta que indefectiblemente conduciría al progreso:

El descubrimiento de las instituciones democráticas de los Estados Unidos es más precioso que el del vapor o la brújula. (...) La bondad de las instituciones de los Estados Unidos es absoluta, porque estas instituciones reposan sobre el reconocimiento de la soberanía del individuo, de ese derecho que todo hombre ha recibido del Creador para gobernarse a sí mismo, de ese derecho de que resulta la soberanía del pueblo, que no es otra cosa que el conjunto de las soberanías individuales (1981, pág. 250).

La soberanía individual norteamericana donde "cada uno es el mejor juez de sus propios intere- ses" (González, 1981, pág. 230), replicada en el país lo llevaría a resolver todas sus dificultades y a alcanzar la civilización. ${ }^{12}$ González idealizaba el principio de soberanía al punto de atribuirle todos los bienes de que gozaban los estadounidenses. Es precisamente allí donde este autor ve el remedio a todos los males políticos, económicos y sociales del país, desconociendo que dicho bienestar se debía en buena parte a la historia de exterminio de las comunidades indígenas, la explotación de mano de obra esclava, la exclusión de las mujeres y las minorías. ${ }^{13}$

En este mismo sentido, Samper llegó a referirse a Estados Unidos como el genio civilizador: “las razas germánicas o del Norte, son las únicas que poseen el genio de la colonización, es decir, de la creación de sociedades civilizadas en regiones bárbaras" (1969, pág. 32). Sin embargo, también advierte en los Estados Unidos debilidades que, según él, le impedirían llegar a una verdadera democracia, tales como el antagonismo entre la raza blanca y los hombres de color, su espíritu invasor, su régimen protector y el antagonismo religioso de los mormones.

Mientras que para Samper (1969) "el espíritu invasor que los americanos han desplegado, ha sido para ellos una causa de debilidad presente

12 De acuerdo con González, "cuando las instituciones permiten al individuo el que él sea el que maneje sus negocios y decida sobre ellos, él piensa constantemente en ellos, adelanta su inteligencia con sus reflexiones, adquiere la conciencia de sus propias fuerzas, robustece su voluntad" (1981, pág. 230).

13 Sobre este particular, Fontana (2001) criticaría la construcción sesgada del ideario democrático estadounidense en cuya historia se omitía cualquier mención sobre esclavitud, conquista a pueblos nativos, opresión a grupos marginados y mujeres: “Una visión que se abstenía de criticar a los "robber barons" creadores de riqueza, y que celebrara el milagro que había engendrado una nación sin clases" (pág. 264). 
y futura, y los llevará a la ruina política, porque la conquista y la república democrática se excluyen mutuamente" (pág. 218), para González dicho espíritu invasor de Estados Unidos redundaría en beneficio del país ocupado y en la prosperidad del mundo en general. Se trataba, en otros términos, de la lucha entre la civilización y la barbarie. ${ }^{14}$ Con lo anterior queda de manifiesto que el liberalismo colombiano del siglo XIX presentaba algunos matices en su interior. Sin embargo, pese a las diferencias que podrían encontrarse entre los pensadores liberales de la época, confluían en ver en los principios liberales el camino a la civilización.

Para González (1981) los principios liberales eran una forma de regeneración a la cual se llegaría luego de reconciliarse los partidos, movidos por el deseo de mejor suerte: "una vez hemos adoptado las disposiciones más liberales; y bajo su influencia bienhechora el país empieza a regenerarse y levantarse de la postración en que estaba" (pág. 108). Por su parte, Samper veía las revoluciones que tuvieron lugar en América Latina en la primera etapa postcolonial, como las vacilaciones propias del infante, las agitaciones normales del progreso y de la transición social y política en un mundo virgen. "Si se quiere, pues tener estabilidad, libertad y progreso en Hispano-Colombia, es preciso que

14 Frente a una eventual ocupación de México por Estados Unidos, González sostuvo que: "Si México es ocupado por los Estados Unidos, México reaparecerá más tarde en la familia de las naciones independientes, poderosa, rica y feliz, después de haber pasado por esta peripecia política, que le es necesaria en mi concepto para consumar su regeneración. Y si México no es ocupado, si conserva su nacionalidad, siempre le habrá resultado un gran bien de que los activos yankees hayan puesto el pie en sus tierras, y emprendido disipar la perezosa somnolencia en que vive el indolente mexicano" (1981, pág. 104). los hombres de estado se resuelvan a gobernar lo menos posible, confiando en el buen sentido popular y en la lógica de la libertad" (Samper, 1969, pág. 229).

La postura liberal de González lo llevó a rechazar el socialismo por considerar que desestimulaba al individuo al intervenir en asuntos que solo le correspondían a este. Con el pretexto de darles a todos igual suma del bien, afirmaba, el comunismo sometía la voluntad particular a la de la comunidad, "el socialismo quiere hacer una masa uniforme compuesta de partes incombinables y sacrificando el valor de las partes" (1981, pág. 232).

De Trazegnies, por su parte, al hablar de las manifestaciones de la modernidad, señala que el liberalismo y el socialismo convergen en el hecho de que son homogeneizadores, que destruyen la multiculturalidad: "La modernidad, ya sea en su versión liberal, ya sea en su versión socialista, pretendió suprimir las diferencias culturales y crear un Derecho homogéneo con vocación de universalidad" (1993, pág. 79).

La modernidad como producto de la llustración, se caracterizó por "una primacía de la razón y, consecuentemente la exaltación de la subjetividad individual" (De Trazegnies, 1993, pág. 79). ${ }^{15}$ González no fue ajeno a esta corriente de pensamiento y, basado en una idea de universalidad y atemporalidad del Derecho, conside-

15 En relación con la idea del Derecho Universal encontramos en Savigny la siguiente alusión: "Debían, además, estos Códigos estar completamente libres de toda histórica influencia, y por obra de una solemne y extraña abstracción, debían adaptarse a todos los pueblos y todos los tiempos" (1977, pág. 40). 
ró que la solución a los problemas económicos y sociales de la Nueva Granada se hallaba en la trasplantación de las instituciones democráticas estadounidenses. Entre las instituciones que conducían a la civilización se encontraba el federalismo. De ahí que González fuera partidario de un gobierno federal donde un gobierno nacional se encargara de los asuntos exteriores mientras otro estatal se ocupara de los asuntos internos:

Nuestra patria debe tener un gobierno general que atienda a sus intereses comunes, represente nuestra nacionalidad en el exterior, nos defienda contra las agresiones extranjeras, y conserve los vínculos que deben unir siempre a todos los colombianos; dejando a los Estados la facultad plena de organizar su gobierno interior (1981, pág. 216).

Montesquieu (1987) sostiene una tesis contraria; para él las leyes tienen un carácter particular acorde con las circunstancias específicas de cada nación:

Las leyes políticas y civiles de cada nación no deben ser otra cosa sino casos particulares en los que se aplica la misma razón humana. Deben ser estas últimas tan ajustadas a las condiciones del pueblo para el cual se hacen, que sería una rarísima casualidad si las hechas para una nación sirvieran para otra (pág. 6).

¿Cómo se llega a incorporar en las instituciones neogranadinas el derecho universal de la soberanía individual? Este es el punto del que me ocupo a continuación.

\section{EL LEGISLADOR REFORMISTA}

En relación con la creación de buenas leyes, González nos habla de grandes legisladores, pero ¿De dónde provienen estos grandes hombres? Si como se expresó anteriormente las clases privilegiadas son las que se oponen a las reformas, ¿De dónde provienen estas últimas?, ¿acaso del pueblo mismo? Si bien González reconoce la democracia como la mejor forma de gobierno, ${ }^{16}$ hace una distinción entre la "democracia ilustrada" y la "democracia bárbara":

Queremos, pues, una democracia ilustrada, una democracia en que la inteligencia y la propiedad dirijan los destinos del pueblo; no queremos una democracia bárbara, en que el proletarismo y la ignorancia ahoguen los gérmenes de la felicidad y traigan la sociedad en confusión y desorden (1981, pág. 134).

El poder de hacer las leyes debe entonces recaer en hombres que ofrecen a la sociedad una garantía de inteligencia (instrucción) o de interés (riqueza). Esta aristocracia de la inteligencia y la riqueza constituye, según él, la base sólida sobre la que reposa la democracia política. González señala que no hay utilidad para la nación en la generalización del derecho a elegir y lo restringe a aquellos que según él demuestren

16 Hobbes (1979) afirma que "donde el interés público y el privado aparecen más íntimamente unidos, se halla más avanzado el interés público" (pág. 153), siendo para él la monarquía el mejor sistema de gobierno por considerar que en esta el interés público y el privado del soberano aparecen unidos. En la democracia, al igual que la aristocracia, sostiene, la prosperidad pública no se corresponde con la fortuna particular y por tanto no es el mejor sistema de gobierno. 
tener "algún discernimiento para elegir los mejores" (pág. 271). ${ }^{17}$

La democracia ilustrada o aristocracia social es, según González (1981), útil para la sociedad porque constituye un aliciente que mueve al ignorante y al pobre a mejorar sus condiciones de vida. Por otro lado, la idea del sufragio universal, fomenta la pereza y conduce a la miseria:

Existan pues, enhorabuena, la aristocracia social, de la inteligencia y de la riqueza, porque estas aristocracias sociales, que son el estímulo para que el ignorante se instruya y el pobre trabaje para ser rico, lejos de ser perjudiciales son sobremanera útiles para la sociedad (1981, pág. 273).

Samper, al igual que González, considera que limitar el sufragio a aquellos ciudadanos que sepan leer y escribir constituye un estímulo para estos y un acto de responsabilidad frente al Derecho y las instituciones. Adicionalmente afirma que "sólo así tendrán los gobiernos y los partidos interés en ilustrar a las masas" (1969, pág. 235).

En aras de garantizar que quienes sean elegidos para hacer las leyes sean los más idóneos, González sostiene que el derecho al voto debe tener una restricción más allá de la edad de los 21 años y no debe admitirse el voto femenino.

17 Como bien señala Fontana, "el llamado sufragio universal no se implementó hasta que se tuvo la seguridad de controlarlo con el fin de que la 'nación de los pobres' no pudiera utilizar sus votos para desalojar del poder a la 'nación de los ricos'” (2010, pág. 139). De acuerdo con este autor, la figura del voto en la mayoría de los países democráticos se limitó a un $4 \%$ o $5 \%$ de la población, los llamados 'ciudadanos' que tenían propiedades suficientes como para suponerles interesados en la conservación del orden social.
Esto último, por ser considerado una potencial causal de conflicto intrafamiliar:

El voto femenino sería introducir el desorden en la familia, que es la base sobre la que descansa el orden de la sociedad; porque esto sería llevar al seno del hogar las pasiones y animosidades de los partidos y privar al ciudadano del único asilo en donde se encuentra el descanso de las agitaciones políticas (1981, pág. 272).

De esto se desprende una nueva pregunta: ¿Esos hombres que ofrecen garantía de inteligencia y de interés, que conforman la democracia ilustrada, son diferentes a los de las clases privilegiadas que se oponen a las reformas? Yo diría que son los mismos. Entonces, si las reformas no provienen de las clases privilegiadas, que son las que conforman la democracia ilustrada, ni del pueblo pobre y sin educación que constituye la "democracia bárbara" ¿de dónde provienen las reformas?

Tal vez, en este punto González coincida con Rousseau en que el legislador sea un ser sabio y extraordinario. Rousseau considera que el pueblo por sí mismo no tiene una voluntad clara y la capacidad necesaria para encontrar el camino que lo conducirá a alcanzar sus metas. Por tanto, este sostiene:

El pueblo, de por sí, quiere siempre el bien; pero no siempre lo ve. La voluntad general es siempre recta; mas el juicio que la guía no siempre es claro. Es preciso hacerle ver los objetos tal como son, y algunas veces tal como deben parecerle; mostrarle el buen camino que busca; librarle de las seducciones de las voluntades particulares (Rousseau, 1975, pág. 65). 
En otras palabras, para Rousseau, el pueblo requiere de un ser superior que lo oriente: “EI legislador es, en todos los aspectos, un hombre extraordinario en el Estado. Si debe serlo por su genio, no debe serlo menos atendiendo a su función" (1975, pág. 67). ${ }^{18}$

Sobre el particular, Mostesquieu (1987) sostiene que en una democracia debe establecerse un senado al que se acceda ya sea por la virtud, la edad o los servicios. Dicho senado deberá identificarse con las instituciones antiguas y las viejas tradiciones, por ser estas indispensables para que reine la armonía entre el pueblo y sus magistrados. De tal suerte "los senadores, imagen de los dioses para el pueblo que los mira, inspirarán sentimientos que llegarán al seno de todas las familias" (pág. 35).

En términos de González, el legislador debe ofrecer garantía de inteligencia. Locke, por su parte, considera que la libertad del individuo radica en la capacidad de razonar:

Si debido a deficiencias que se salen del curso normal de la naturaleza alguien no llega a alcanzar un grado tal de razón como para suponerlo capaz de conocer la ley y, por consiguiente, tampoco para vivir bajo tal ley, no podrá convertirse en un hombre libre, nunca podrá disponer libremente de su propia libertad, sino que permanecerá bajo la tutela y el gobierno de otros mientras su entendimiento no sea capaz de desempeñar esa tarea (1991, pág. 246).

18 Esto resulta en cierta forma paradójico, dado que según el mismo Rousseau "El pacto social establece entre los ciudadanos una igualdad tal, que se comprometen todos bajo las mismas condiciones y, por tanto, deben gozar todos los mismos derechos" (1975. pág. 58).
En todo caso, tanto González como Locke y Rousseau reconocen la existencia de unos individuos superiores a otros. Le corresponderá a estos seres dotados de una razón y una inteligencia extraordinarios gobernar sobre los demás seres ignorantes, bárbaros, carentes de juicio claro y enseñarles lo que es lo mejor para ellos.

\section{CONCLUSIONES}

La cara liberal que nos presenta Florentino González hace manifiestas las contradicciones de la modernidad ilustrada propia del siglo XIX. Por un lado, se utiliza el discurso de la soberanía individual y de la reivindicación de las clases oprimidas, pero, por el otro, se sostiene la llamada aristocracia social que da participación solo a aquellos que tienen instrucción y riqueza excluyendo al pueblo en general. La soberanía del individuo no resulta siendo más que la soberanía del hombre educado y rico. Es una forma refinada de colonización basada en un proyecto homogeneizador que busca destruir las costumbres del pueblo indígena, negro y mestizo que le son contrarias, considerándolas como un obstáculo para la idea impuesta de civilización.

El liberalismo ilustrado de González es una forma refinada de colonización, toda vez que se basa en la idea de un supuesto Derecho universal que, en últimas, no es más que un derecho particular impuesto por las grandes potencias. Se trata de un modelo de Derecho idealizado que considera bárbaro todo lo que le es contrario. La democracia ilustrada es presentada 
como una forma de gobierno benéfica que estimula al ignorante a instruirse y al pobre a trabajar, pero que encierra un discurso legitimador de un sistema opresor. Es un discurso que indirectamente sostiene que el pueblo es ignorante y pobre por holgazanería, carente de espíritu emprendedor y abandonado a sus animosidades. Es una tesis que llega a justificar la expoliación indígena, la explotación esclava, la segregación racial y la exclusión de las mujeres y de las minorías como el precio que hay que pagar para lograr el progreso.

Por último, lo interesante de esta tesis de Florentino González, es que en muchos aspectos se encuentra aún vigente. Más de un siglo después se siguen viendo las instituciones norteamericanas como el norte al que se debe apuntar. Las intervenciones bélicas, políticas y económicas que realiza Estados Unidos en los países del Medio Oriente se siguen viendo como la conquista de la civilización sobre la barbarie. Estas políticas liberales de Estados Unidos y otros países del Norte, fuertemente colonizadoras y homogeneizadoras siguen siendo entendidas como el camino hacia el progreso, del cual se benefician no solo el país intervenido sino el mundo en general.

En Colombia, la Iglesia sigue interviniendo en los asuntos del Estado y segregando una parte de la población. Esta sigue, por ejemplo, incidiendo en temas tan importantes como la definición de familia, la unión en matrimonio y la posibilidad de adoptar de personas del mismo sexo. Las costumbres y tradiciones más arraigadas de los pueblos indígenas y afrodescendientes siguen siendo un obstáculo para el pretendido progreso liberal que proponen las empresas extractivas. La trasplantación de las instituciones "civilizadas" sigue siendo vista como el camino hacia el desarrollo. Solo por poner un pequeño ejemplo, ¿por qué los jueces en nuestro país tienen ahora que llevar una toga?

Algunas cosas han cambiado desde que Florentino González formulara los planteamientos aquí abordados: el derecho al sufragio no está condicionado al nivel de instrucción o capacidad económica; las mujeres tienen, al menos frente a la ley, igualdad de derechos; y existe una pluralidad de normas que buscan proteger la diversidad cultural. Empero, el colonialismo institucional estadounidense y europeo sigue estando muy presente.

\section{Referencias}

Blancarte, R. (Coord.). (2008). Los retos de la laicidad y la secularización en el mundo contemporáneo. México, D. F.: El Colegio de México.

Burke, E. (1942). Textos políticos. México, D. F.: Fondo de Cultura Económica.

Calvez, J. (1958). El pensamiento de Carlos Marx. Madrid: Taurus Ediciones.

De Trazegnies Granda, F. (1993). Postmodernidad y Derecho. Bogotá: Editorial Temis.

Fitzpatrick, P. (1998). La mitología del derecho moderno. México, D. F.: Siglo Veintiuno Editores. 
Fontana, J. (2001). La historia de los hombres: el siglo XX. Barcelona: Crítica.

Fontana, J. (2010). Europa ante el espejo. Barcelona: Crítica.

González, F. (1981). Escritos políticos, jurídicos y económicos. Bogotá: Instituto Colombiano de Cultura.

Hobbes, T. (1979). El Leviatán. (A. Escohotado, Trad.). Madrid: Nacional.

Locke, J. (1960). Dos ensayos sobre el gobierno civil. Madrid: Colección Austral Espasa Calpe.

Lukacs, G. (1986). El desarrollo filosófico del joven Marx. Bogotá: Universidad Nacional de Colombia.

Marx, K. (2009). Sobre la cuestión judía. BarceIona: Anthropos/Universidad Autónoma Metropolitana.
Montesquieu, C. (1987). Del espíritu de las leyes. México: Editorial Porrúa.

Múnera, A. (2005). Fronteras imaginadas: la construcción de las razas y de la geografía en el siglo XIX colombiano. Bogotá: Planeta.

Múnera, A. (2011). Tiempos difíciles. La república del XIX: una ciudadanía incompleta. Cartagena de Indias: Ediciones Plumas de Mompox S. A.

Rousseau, J. (1975). Contrato social. Madrid: Espasa Calpe.

Samper, J. (1969). Ensayo sobre las revoluciones políticas y la condición social de las repúblicas colombianas. Bogotá: Universidad Nacional de Colombia.

Savigny, F. (1977). De la vocación de nuestro siglo para la legislación y la ciencia del Derecho. Buenos Aires: Biblioteca Jurídica Heliasta. 